\title{
Tolerance of disturbance by humans in long-time resident and recent colonist urban doves
}

\author{
Jemma Gendall', Alan Lill ${ }^{1,2^{*}}$ and Juliey Beckman ${ }^{3}$
}

\begin{abstract}
Background: A critical trait for successful urban dwelling by birds is the ability to tolerate high levels of disturbing stimulation by humans. If such tolerance is partly acquired gradually after colonization, species with a long history of residence in cities are likely to be more tolerant of such stimulation than recent urban colonists, but this has not often been tested.

Methods: We tested whether introduced Rock (Columba livia) and Spotted (Streptopelis chinensis) Doves, historically long-term residents of Melbourne, Australia, were more tolerant of disturbance by humans than the very recent colonist, the native Crested Pigeon (Ochyphaps lophotes) by comparing the Flight Initiation Distances (FID) and time allocations to vigilance during foraging of all three species in urban Melbourne. That all three species are members of the Columbiformes reduces the possibility that any species differences in tolerance are simply phylogenetic in origin.

Results: Flight initiation distance was shorter in Rock Doves than in the other two species, which did not differ in approachability by a human. Rock Doves retreated from an approaching human mainly by walking a relatively short distance, Crested Pigeons mainly by running a relatively short distance and Spotted Doves primarily by flying a comparatively long distance. The time allocation to anti-predator vigilance of Rock Doves was smaller than that of the other two species, whose allocations were similar.

Conclusions: The very recent colonist of eastern Melbourne, the Crested Pigeon, was not the least tolerant of disturbance by humans of the three related species. Natural selection for tolerance therefore probably cannot entirely explain the pattern of tolerance evident among these urban dove species and behavioural flexibility is probably involved. Length of residency in a city is not an infallible guide to a species' level of tolerance of disturbance by humans.
\end{abstract}

Keywords: Doves, Urban environment, Flight initiation distance, Vigilance, Behavioural flexibility

\section{Background}

Increasing urbanization worldwide has generated both greater awareness of the need to conserve urban biodiversity and an increase in the research required to inform that conservation process (Dunn et al. 2006; DeStefano and Degraaf 2008). Urbanization dramatically changes the natural environment; some species thrive under the altered circumstances ('urban exploiters' and 'adapters'), but others ('urban avoiders') are unable to adjust to the altered environment (Blair 2001). We need to understand what determines this disparity in order to successfully conserve

\footnotetext{
* Correspondence: A.Hirund@gmail.com

${ }^{1}$ Wildlife Ecology and Conservation Physiology, School of Biological Sciences, Monash University Clayton Campus, 3800 Victoria, Australia

${ }^{2}$ School of Life Sciences, La Trobe University, 3086 Victoria, Australia

Full list of author information is available at the end of the article
}

urban biodiversity and ensure the survival of species sensitive to urbanization. One key to successful urban living by birds is an ability to tolerate high levels of disturbance by mostly harmless people (Price 2008). Urban living would not be viable, because critical activities would be curtailed, if birds: (a) spent a large proportion of the day monitoring their environment for stimuli posing little real threat to their survival, or (b) fled long distances rapidly in an energetically-expensive manner when approaching humans were still a long distance away (Frid and Dill 2002).

Theoretically, the tolerance of human proximity necessary to facilitate urban living could eventuate in one of several ways: (a) cities might only be colonized by bird species whose members are all relatively bold as a result of natural selection for boldness in the exurban environment, 
(b) urban members of a colonizing species might rapidly become bolder than ex-urban con-specifics through genetic selection (Møller 2008), (c) cities might only be settled by bolder subsets of a species' members through a sorting process (Atwell et al. 2012), or (d) birds that colonize cities might adjust to high human population densities through behavioural plasticity that allows them to rapidly learn that urban humans mostly pose little threat and do not warrant extensive surveillance or early, rapid fleeing responses (Lima and Bednekoff 1999; Weston et al. 2012).

Species that have genetically adapted to cities for a large number of generations should have shorter Flight Initiation Distances (FID) and smaller relative time allocations to anti-predator vigilance than recent urban colonists. By genetic adaptation we mean adjustment to inhabiting the urban environment that comes about through natural selection (i.e. beneficial genetic change). Møller (2008) demonstrated such a trend for FID in some Western European bird species, but few other studies have addressed this issue, particularly in Australia where cities tend to have a shorter history than many European conurbations. Even where tolerance of disturbing stimulation by humans in cities is primarily achieved through learning, if intra-specific observational, rather than experiental, learning is involved, we might still expect that a very recent urban colonist species would be less tolerant of human proximity than more established species. This would be so because the abundance of models from which to learn tolerance would presumably be relatively low during the colonization process. In birds, FID is a useful, easilyobtained metric of boldness and tolerance of disturbance by humans, with both theoretical and management significance (Weston et al. 2012; Møller et al. 2014; Vines and Lill 2015). Vigilance effort has been used less often in this context, but has potential as a tolerance metric (Fernández-Juricic and Schroeder 2003).

The Rock Dove (Columba livia) is believed to have been introduced to Australia around the time of British settlement in 1788, but the first recorded releases in the state of Victoria were in the 1870s (Long 1981). It is an 'urban exploiter' that lives commensally with humans in cities in Australia and worldwide (Robbins 1995; Higgins and Davies 1996). Human food waste spillage and food deliberately provided by humans ('volunteer' food) comprise a significant proportion of its urban diet (Mulhall and Lill 2011). The Spotted Dove (Streptopelia chinensis), another urban exploiter, was possibly introduced to Melbourne in the 1860s, but definitely released in the city from 1870-1874 (Long 1981). It depends less on human food waste than the Rock Dove, but also consumes livestock food (Frith et al. 1976; Mulhall and Lill 2011). In contrast, the endemic Crested Pigeon (Ochyphaps lophotes) is an 'urban adapter' that is less commensal than the other two dove species and consumes only a small volume of anthropogenic food (Frith et al. 1974). It has settled in most major east coast temperate zone cities, but only colonized Melbourne's eastern suburbs in the last $15-20$ years (A. Lill, personal observation).

We predicted that in Melbourne the Crested Pigeon would be less adjusted to human proximity than the Rock Dove and Spotted Dove. Not only have the latter two species been established in urban Melbourne far longer than the Crested Pigeon, but the original founder individuals of at least the Rock Dove came from overseas populations that already had a substantial history of close contact with humans. We tested this prediction by contemporaneously: (a) comparing the FID and retreat behaviour of members of the three species to an approaching observer, and (b) measuring the mean proportion of daylight hours spent by the three species in vigilance (i.e. surveillance for threatening stimuli). We reasoned that the predicted lesser tolerance of disturbance by humans of Crested Pigeons would be manifested in fleeing from approaching people earlier than the other species and in spending a greater proportion of terrestrial foraging time in surveillance for approaching humans.

\section{Methods}

\section{Study area}

The study was conducted in the austral autumn and winter (April-August, 2011) at 150 sites spread widely throughout the eastern suburbs of Melbourne, Australia $\left(37.84^{\circ} \mathrm{S}\right.$, $144.98^{\circ} \mathrm{E}$ ). The city has a human population of over 4 million and extends over $9,900 \mathrm{~km}^{2}$. The study sites, mainly in streets, public parks, recreation reserves and on sports fields, were at least $1 \mathrm{~km}$ apart to preclude repeated sampling of unmarked individuals.

\section{Measurement of behaviour}

Observations were made on all days of the week between 07:00-11:00 and 13:00-17:00 AEST. At each haphazardly chosen site, two observations per species on two different focal individuals were made for each behavioural variable, whenever possible. Only birds that were on the ground and active were recorded. In conjunction with the behavioural records, we also recorded categorically $(0,1-5$ or $>5$ ) several co-variates within $10 \mathrm{~m}$ of the focal bird that could potentially influence its behaviour: (1) refuges from predators (e.g. buildings or vegetation cover), (2) potentially threatening stimuli (e.g. predators or moving vehicles), (3) humans and (4) con-specifics and hetero-specific pigeons. Size of the flock of which the focal bird was a member was also noted. All these co-variates have been demonstrated to influence FID in various bird species (Blumstein 2006; Weston et al. 2012). Based on Australian Bureau of Statistics (2011) data, sites were roughly categorized as having an estimated low $\left(\leq 500\right.$ people $\left./ \mathrm{km}^{2}\right)$ or high $\left(>2,500\right.$ people $\left./ \mathrm{km}^{2}\right)$ human population density. 


\section{Flight initiation distance}

The same observer conducted all FID measurements. She always approached the focal bird in a straight line at a steady pace $(0.5-1 \mathrm{~m}$ per sec) and measured the distance $( \pm 1 \mathrm{~m})$ between herself and the bird at which her approach stimulated it to retreat. The Starting Distance (distance from observer's starting point to focal bird's initial location) was also recorded. These distances were measured with a Bushnell Yardage Pro Sport $450^{\text {ma }}$ laser rangefinder. The focal birds' mode of retreat (walking, running or flying) and the (unequal) categorical distances that they retreated $(\leq 5,5.1-10$ and $>10 \mathrm{~m})$ were also recorded. The second recording from a different flockmember was made at least $1 \mathrm{~min}$ after the first one to avoid 'carry-over' effects.

\section{Vigilance time allocation}

Time investment by foraging doves in vigilance (head-up, visual scanning) was measured for focal individuals over 1-5 min periods using instantaneous sampling (Martin and Bateson 2007) with a 5-sec fixed interval. Co-variates were recorded as outlined above. A second recording from a different member of the same flock was made at least 30-sec after the first one. Although this could potentially reduce independence of the data, there are precedents for using this procedure for constructing time-activity budgets in flocking species (e.g. Magrath and Lill 1983). Vigilance records were obtained from a distance and at a time when the observer's presence or activity were unlikely to be influencing the focal bird's behaviour (McGiffin et al. 2013).

\section{Data analysis}

Statistical analysis was conducted with $\mathrm{R}$ version 2.10.1. Data were inspected for conformity with the assumptions of the various significance tests used. To increase statistical power of some analyses, some co-variates were excluded and some categorical variables were pooled where it was evident that their inclusion did not contribute to the explanatory power of the analysis. Inclusion of second records from a flock did not affect the outcome of analyses, so we included all vigilance allocations and FIDs recorded. As starting distance had a strong influence on FID (see Blumstein 2003), we used adjusted FID (FID ${ }_{\text {adj }}$ ), the residuals from an ordinary least squares regression of FID on starting distance, in analyses of tolerance of the doves of an approaching observer. Chi square contingency tests were used to examine species differences in mode and distance of retreat from an approaching observer.

Due to the FID and vigilance data's non-linearity and the complexity of the behavioural interactions, we used non-linear Conditional Inference Tree and Random Forests models to characterise which variables and co-variates explained most of the variation in FID $_{\text {adj }}$ and the time allocation to vigilance. Conditional Inference Tree models use non-biased splitting and are robust to co-linearity of the variables (Zuur et al. 2007). They progressively split the data into sub-groups with the smallest within-group variation and the largest between-group variation in the tree. Random Forests models are collections of categorical and regression tree analyses (Liaw and Wiener 2002) which can indicate the relative explanatory power of various predictor variables to explain variation in a response variable (Breiman 2001).

\section{Results}

\section{Flight initiation distance}

Mean actual FIDs $(\mathrm{m})$ of the three species were: Rock Dove $5.3 \pm 0.4$, Spotted Dove $14 \pm 0.7$ and Crested Pigeon $13.4 \pm 0.6$. Conditional Inference Tree analysis (Figure 1) indicated that FID adj was significantly shorter in the Rock Dove than in the other two species, which did not differ in approachability. In Rock Doves, FID $_{\text {adj }}$ was also significantly shorter where estimated human population density was higher. Random Forests analysis indicated that for the three species considered collectively, species identity had the strongest proportional influence on FID $_{\text {adj }}(76 \%)$, with estimated human population density (14\%), habitat type and refuge type (each $\sim 7 \%$ ) exerting much smaller influences. No other measured co-variate had any effect on FID adj. .

\section{Retreat mode and distance}

The three species varied in their mode of retreat from the approaching observer $\left(\chi_{(4)}^{2}=102.5, P<0.001\right)$ (Figure 2$)$. Inspection of the standardized residuals (Table 1) indicates that Rock Doves walked away more and flew away less than expected, Crested Pigeons ran away more and flew away less than expected, and Spotted Doves flew away more but walked and ran away less than expected. The species also varied in the distance that they retreated from the observer $\left(\chi_{(4)}^{2}=86.2, P<0.001\right)$ (Figure 2$)$. The standardized residuals (Table 1 ) indicate that Rock Doves fled $\leq 5 \mathrm{~m}$ more and $>10 \mathrm{~m}$ less than expected, Spotted Doves fled $>10 \mathrm{~m}$ more and $\leq 5 \mathrm{~m}$ less than expected and Crested Pigeons retreated 5.1-10 m more and $>10 \mathrm{~m}$ less than expected.

\section{Vigilance time allocation}

Rock Doves' ground-foraging occurred fairly equally in the quite open habitat of public parks (45.7\% of observations) and the more visually obstructed habitat of streetscapes (43.3\%), but much less on very open sports fields (11.0\%). Spotted Doves' ground-foraging occurred mainly in streetscapes (78.5\% of observations) and much less in parks (13.5\%) and on sports fields (8.0\%). Ground-foraging of Crested Pigeons took place mostly on sports fields $(63.0 \%$ 


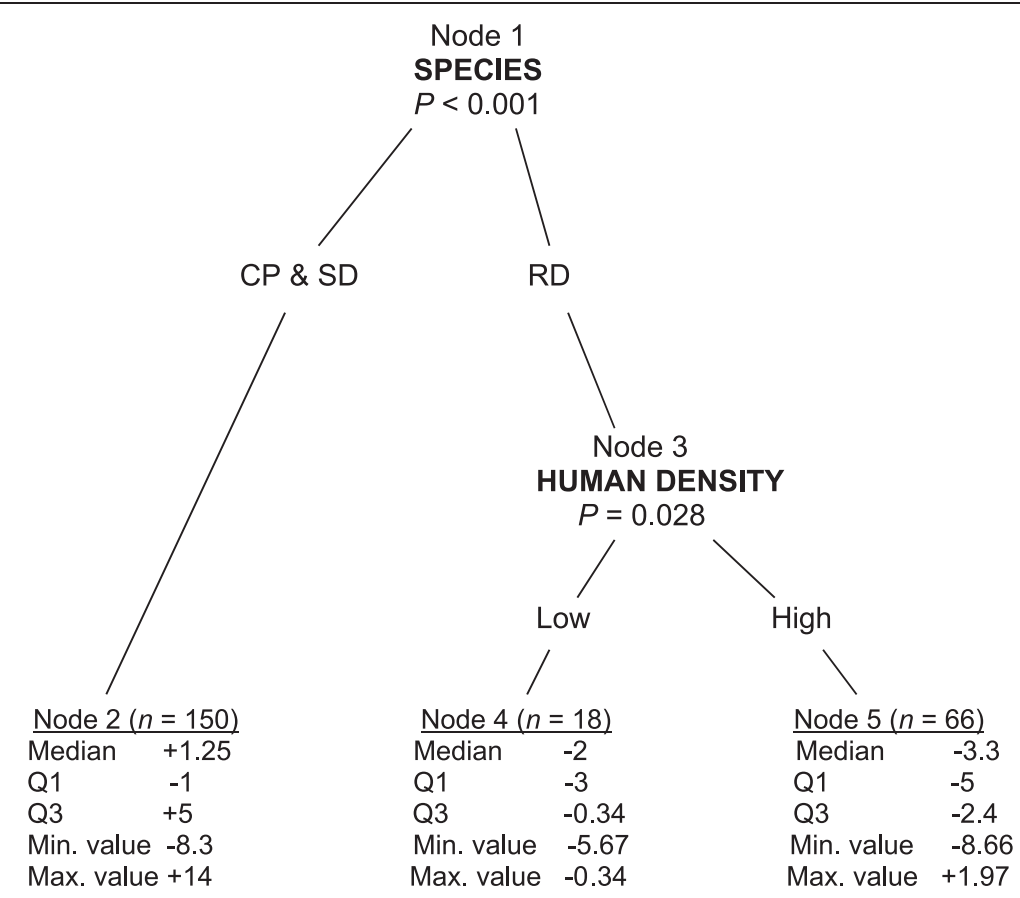

Figure 1 Conditional Inference Tree model for adjusted Flight Initiation Distance in three urban dove species. $C P=C$ rested Pigeon, $S D=S p o t t e d$ Dove and $\mathrm{RD}=$ Rock Dove. Modelling conducted on arcsine square-root transformed data. Summary statistics for Nodes 2, 4 and 5 on a scale from -15 to +15. Q1 and Q3 are first and third quartiles, respectively. Minimum and maximum values do not include outliers.

of observations), far less in more visually obstructed streetscapes (23.6\%) and least in parks (13.4\%).

Conditional Inference Tree analysis indicated that the vigilance time allocation of ground-foraging Rock Doves (mean $6.0 \pm 0.9 \%, n=87$ ) was significantly smaller than that of either Spotted Doves $(15.4 \pm 1.5 \%, n=67)$ or Crested Pigeons $(15.5 \pm 1.9 \%, n=87)$, whose allocations were similar (Figures 3 and 4). Vigilance allocation was also greater when flock size was $\leq 5(20.6 \pm 2 \%$ of time $)$ than when it was $>5$ individuals $(10.7 \pm 1 \%)$ in Spotted Doves and Crested Pigeons, but was unaffected by flock size in Rock Doves (Figure 4). Random Forests analysis indicated that for the three species considered collectively, species $(40.0 \%)$ and flock size $(25.0 \%)$ had the greatest proportional influences on vigilance allocation, with the presence of con-specifics also exerting about a 15\% proportional influence. All other co-variates had a proportional influence $\leq 5 \%$.

\section{Discussion}

The Rock Dove had the shortest FID adj to an approaching observer, the slowest dominant mode of retreat (walking) and the shortest principal retreat distance. However, contrary to our prediction, the Crested Pigeon had a similar $\mathrm{FID}_{\text {adj }}$ and vigilance time allocation to the Spotted Dove, and a slower dominant mode of retreat and shorter average retreat distance than the latter species.

\section{Flight initiation distance}

Among bird species, longer FIDs are variously associated with greater body size, older age at first reproduction, omnivory and carnivory, cooperative breeding and habitat 'openness' (Blumstein 2006). Among urban birds, species that have genetically adapted to cities for many generations have shorter FIDs than recent urban colonists (Møller 2008). However, for the species in the present study, none of these traits explained the observed disparities in FID. The largest species, the Rock Dove (34.5 cm mean total length), actually had a significantly smaller FID adj than the other species, and the smallest species, the Spotted Dove $(30.5 \mathrm{~cm})$, had a similar FID adj to the slightly larger Crested Pigeon $(32.5 \mathrm{~cm})$. All three related species are granivores, differing substantially in their diet only in the volume of human food waste consumed in the urban environment (Higgins and Davies 1996; Mulhall and Lill 2011). None of them has been recorded breeding cooperatively to any significant extent (Ford et al. 1988).

Møller et al. (2014) showed that, particularly in Europe, farmland birds tended to have longer FIDs than those in other habitats. This may be related to both the declining bird population densities and the relative lack of cover (and hence birds' greater vulnerability to predation) in agricultural land. Rock Doves, which had the shortest mean FID $_{\text {adj }}$, foraged mainly and equally in fairly open public parks and more visually obstructed streetscapes. 

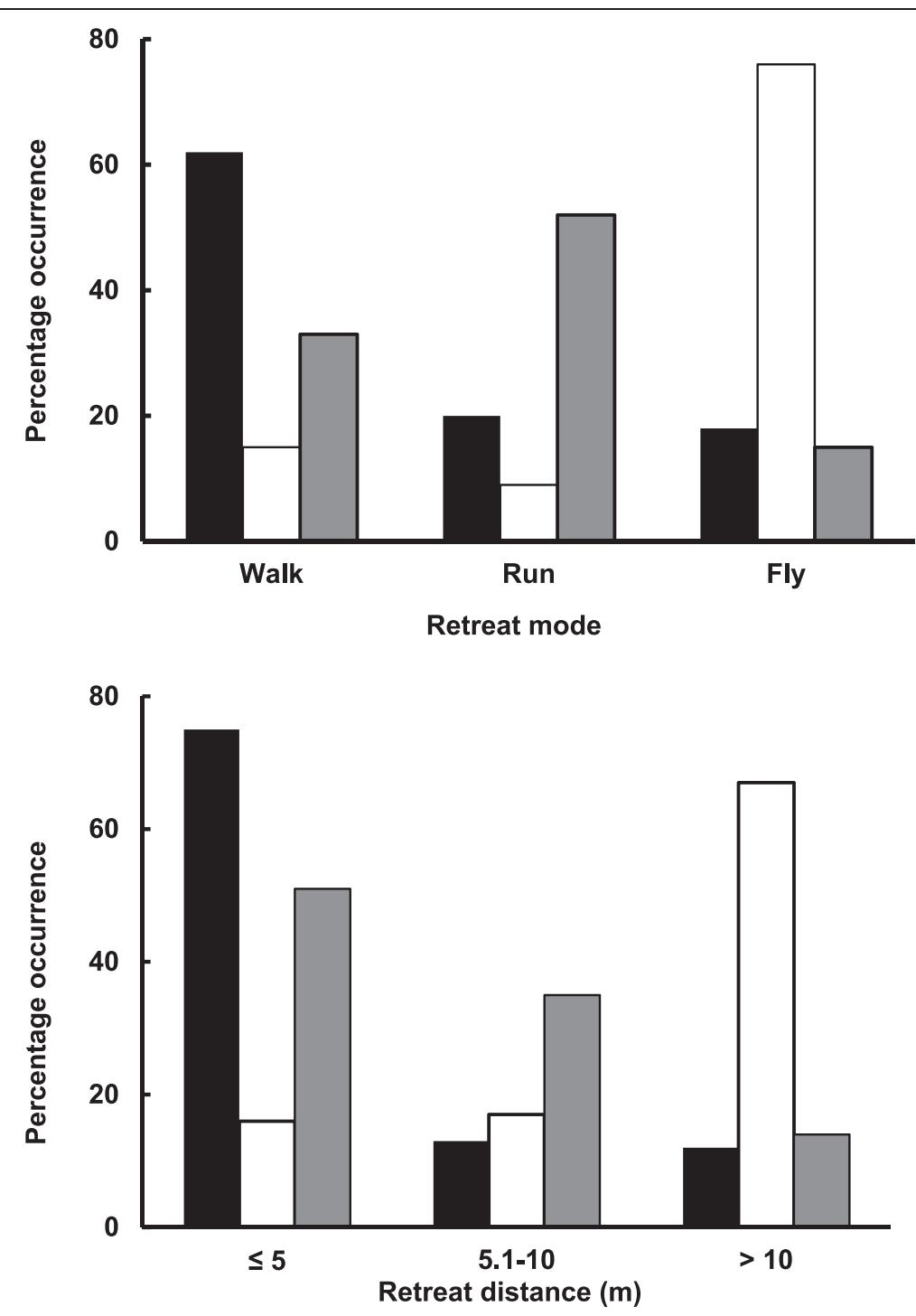

Figure 2 Retreat mode and distance of three urban dove species to an approaching observer. Black columns $=$ Rock Dove, white columns $=$ Spotted Dove and grey columns $=$ Crested Pigeon. $n=234$.

Table 1 Standardised residuals for chi square analyses of retreat mode and distance of urban doves

\begin{tabular}{llll}
\hline Species & & & \\
\hline Retreat mode & Crested Pigeon & Rock Dove & Spotted Dove \\
Walk & -0.8 & $\mathbf{+ 3 . 6 9}$ & $\mathbf{- 3 . 2 1}$ \\
Run & $\mathbf{+ 4 . 2}$ & -1.14 & $\mathbf{- 2 . 9 1}$ \\
Fly & $-\mathbf{2 . 8 5}$ & $\mathbf{- 2 . 8 2}$ & $\mathbf{+ 5 . 8 7}$ \\
Retreat distance (m) & & & \\
$\leq 5$ & +0.35 & $+\mathbf{3 . 4 9}$ & $-\mathbf{4 . 0 4}$ \\
$5.1-10$ & $+\mathbf{2 . 4 4}$ & -1.63 & -0.74 \\
$>10$ & $-\mathbf{2 . 5}$ & $-\mathbf{3 . 0 5}$ & $\mathbf{+ 5 . 7 4}$ \\
\hline
\end{tabular}

Residuals $>2$ in bold.
However, Spotted Doves and Crested Pigeons, which had a similar mean FID $_{\text {adj, }}$ contrasted in foraging habitat 'openness', the former mostly using streetscapes with many visual obstructions and the latter very open sports fields. The Rock Dove, which has probably been present in Melbourne longest (possibly for $>200$ years), was the least wary of humans. However, whilst the Spotted Dove, which has been resident in the city probably for c. 150 years, was more wary of human proximity than the Rock Dove, it was also more wary than the very recent urban colonizer, the Crested Pigeon. Our comparison of three dove species in the urban environment substantially controlled for purely phylogenetic influences on tolerance of disturbance by humans. However, it must be conceded that it is probably less likely to reveal the particular influences on FID 


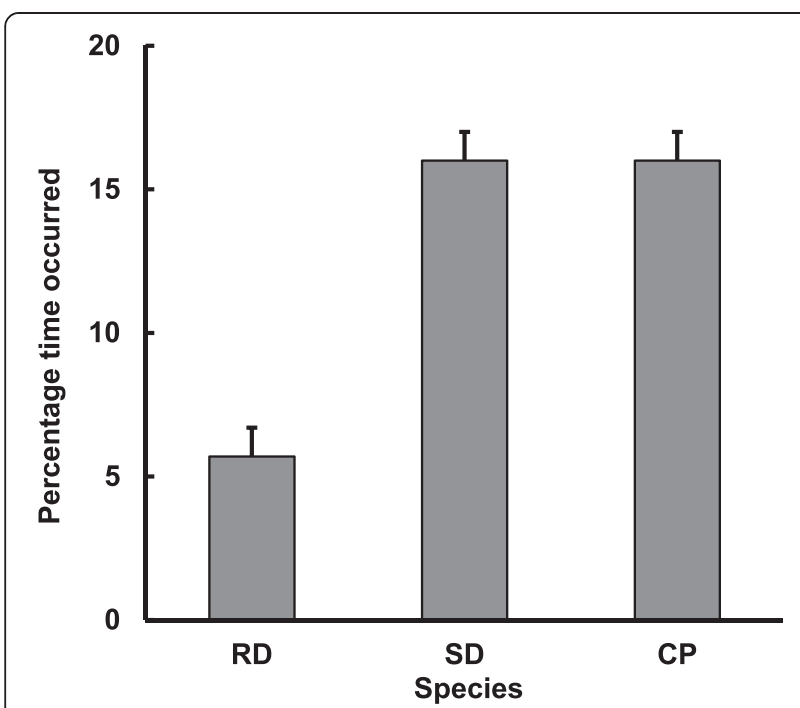

Figure 3 Mean $( \pm \mathrm{SE})$ proportional time spent in vigilance by three urban dove species. $\mathrm{RD}=$ Rock Dove, $\mathrm{SD}=$ Spotted Dove and $\mathrm{CP}=$ Crested Pigeon.

of the type listed above than a phylogenetically broader comparison.

Natural selection for tolerance of human proximity may have occurred in urban Rock and Spotted Doves, but it cannot plausibly explain the fact that Crested Pigeons were more tolerant than Spotted Doves. It is possible that the observed pattern of tolerance occurred because Crested Pigeons as a species, or the subset of urban founder Crested Pigeons, were bolder than Spotted Doves even after generations of selection for tolerance in the latter species. However, it seems more likely that behavioural flexibility was involved in the greater tolerance exhibited by Crested Pigeons. Such greater flexibility could theoretically be related to relative brain size, which is significantly positively correlated with urban colonizing ability in some birds (Malakov et al. 2011), but was not compared among the present study species. However, Guay et al. (2013) have shown that at least in shorebirds brain volume is not correlated with FID. FID being shorter where estimated human population density was higher in the present investigation could be attributable to either habituation or differential settlement by individuals varying inherently in tolerance of disturbance.

\section{Vigilance time allocation}

Anti-predator vigilance is another variable reflecting tolerance of human and predator proximity (Fernández-Juricic and Schroeder 2003). Greater investment in vigilance can increase the distance at which approaching predators and people are detected and/or the probability of detecting them. This enhanced detection ability gives the bird more

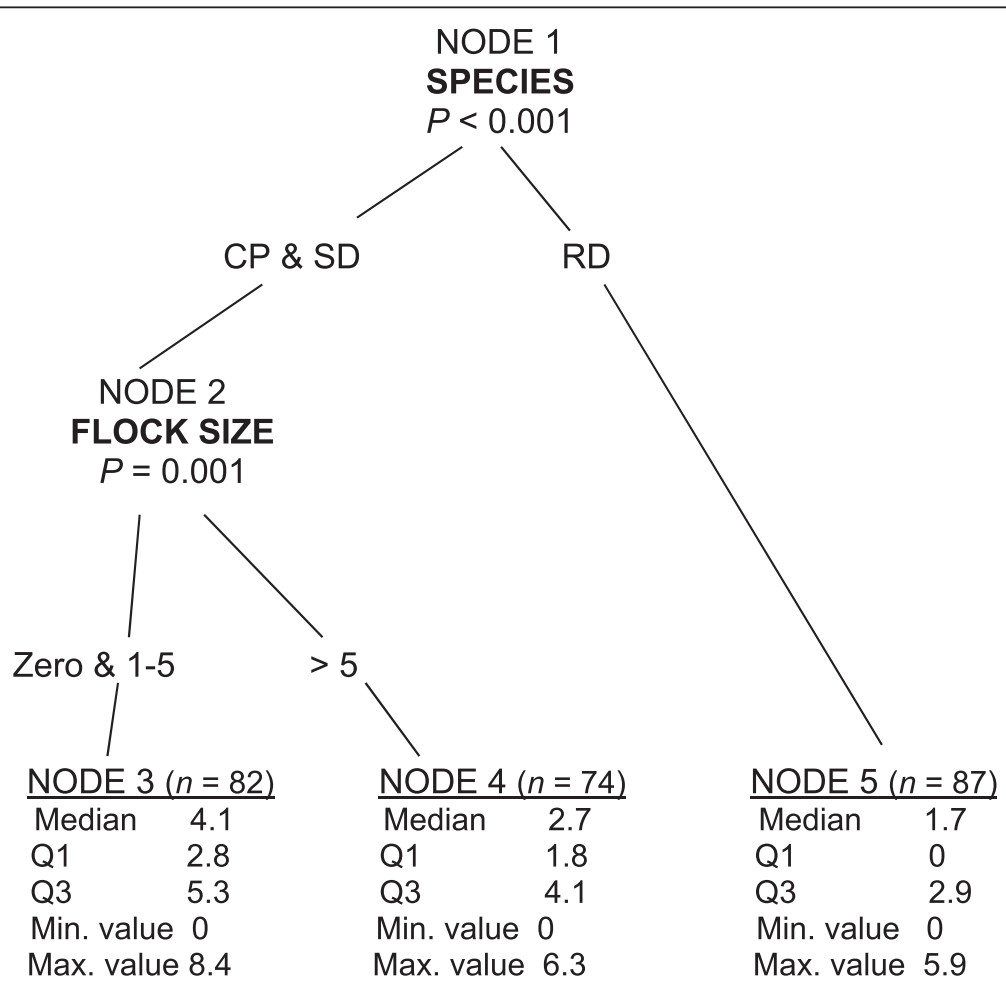

Figure 4 Conditional Inference Tree model for proportional time allocation to vigilance in three urban dove species. $\mathrm{CP}=\mathrm{Crested} P$ igeon, $\mathrm{SD}=$ Spotted Dove and RD = Rock Dove. Modelling conducted on arcsine square-root transformed data. Summary statistics for Nodes 3, 4 and 5 on a scale from 0 to 10. Q1 and Q3 are first and third quartiles, respectively. Minimum and maximum values do not include outliers. 
flexibility to adaptively increase or decrease FID, depending on other relevant variables (e.g. perceived predation risk, Lima and Dill 1990; body mass, Creswell 1995). Fernández-Juricic and Schroeder (2003) showed that Spot-winged Pigeons (Columba maculosa) had a greater proportional time allocation to vigilance and a longer mean FID than co-habiting, smaller Eared Doves (Zenaida auriculata). Presumably for Spot-winged Doves the optimal adaptive response if predators are detected at a great distance is, for whatever reason, to flee early. In our investigation, Spotted Doves and Crested Pigeons seemed to have this greater flexibility to adaptively adjust their FID. They had a significantly greater proportional vigilance allocation than Rock Doves and hence probably a superior ability to detect approaching predators and people, and they retreated from an approaching human significantly earlier than Rock Doves. As Rock Doves in Melbourne are directly fed by humans much more than the other two species, they may have downregulated anti-predator surveillance as the risk posed by people is perceived as being smaller (Lima and Bednekoff 1999).

The similar vigilance budgets of Spotted Doves and Crested Pigeons are intriguing, because the former forages in a more visually obstructed habitat than the latter and consequently might be expected to spend more time being vigilant (Lazarus and Symonds 1992). However, Fernández-Juricic and Schroeder (2003) found that proportional visual scanning time actually decreased as visually obstructive tree cover increased for urban Spot-winged Pigeons and Eared Doves, so the greater level of visual obstruction in streetscapes might be contributing to the similarity in vigilance budgets of Spotted Doves and Crested Pigeons. Conceivably, at high levels of visual obstruction vigilance may become relatively ineffective and be downregulated. The observation that vigilance effort of Spotted Doves and Crested Pigeons was less in larger flocks accords with many, but certainly not all, findings for other bird species (Beauchamp 2008), but it is intriguing that the highly gregarious Rock Doves did not exhibit the same relationship. Currently we know too little about natural predation on these three urban doves to factor it into the vigilance formula.

Whilst it is valid and informative to compare bird species' surveillance for predators by measuring relative vigilance time allocations, two qualifications are pertinent. First, some species' visual fields probably permit surveillance for predators during head-down foraging (FernándezJuricic et al. 2008), although this may be less of an issue when, as here, closely-related species (which probably have similar visual fields) are being compared. Second, even when species' proportional vigilance time allocations are similar, differences in scanning regime structure may nonetheless result in disparate predator detection efficacies (Fernández-Juricic 2012). These aspects of vigilance require examination in the doves investigated here.

\section{Conclusions}

The Rock Dove, probably the earliest of the study species to have colonised Melbourne, was the most tolerant of human disturbance, having the shortest FID and smallest proportional vigilance effort. However, the Crested Pigeon, the most recent of the three species to have colonised the city, was as, or more, tolerant of disturbance by humans as the second-longest resident, the Spotted Dove. We conclude that:

(1)genetic selection cannot entirely explain the pattern of tolerance of disturbance by humans observed among the study species and behavioural flexibility appears likely to be involved

(2) more generally, length of residency in a city is not an infallible guide to a species' relative level of tolerance of disturbance by humans

(3)logically, we might predict that FID and vigilance effort would be positively correlated in bird species communities and Fernández-Juricic and Schroeder (2003) provide some supporting evidence for such a correlation. Our observations were also consistent with this prediction. Vigilance effort therefore has potential as a metric of tolerance of disturbance in urban birds. However, we still need much more information on the identity and abundance of natural predators in cities to fully understand the implications of interspecific variation in vigilance effort.

Our study was essentially a 'snapshot' of the current tolerance of disturbance by humans of three dove species in the urban environment. Longitudinal studies of recent urban colonists and their exurban conspecifics would be very demanding, but would allow us to determine if and how tolerance of such disturbance alters through the various stages of urban colonization, from initial settlement to widespread establishment. This would help in defining the relative roles of genetic adaptation and behavioural flexibility in adjusting to disturbance by humans and identifying the specific influences on the acquisition of tolerance to such disturbance.

\section{Competing interests}

The authors declare that they have no competing interests.

\section{Authors' contributions}

JG collected all the field data and conducted much of the data analysis. AL was involved in project conception and management, some data analysis and wrote the manuscript. JB was involved in project conception and management. All authors read and approved the final manuscript. 


\section{Acknowledgements}

We thank Christopher P. Johnstone for statistical assistance. The study was approved by the Animal Ethics Committee of the School of Biological Sciences, Monash University.

\section{Author details}

${ }^{1}$ Wildlife Ecology and Conservation Physiology, School of Biological Sciences, Monash University Clayton Campus, 3800 Victoria, Australia. ${ }^{2}$ School of Life Sciences, La Trobe University, 3086 Victoria, Australia. ${ }^{3}$ Present address: College of Medicine, Biology and Environment, Australian National University, Canberra, ACT, Australia.

Received: 10 December 2014 Accepted: 17 March 2015

Published online: 01 June 2015

\section{References}

Atwell JW, Goncxalo C, Cardoso D, Whittaker J, Campbell-Nelson S, Robertson KW, Ketterson ED (2012) Boldness behavior and stress physiology in a novel urban environment suggest rapid correlated evolutionary adaptation. Behav Ecol 23:960-969

Beauchamp G (2008) What is the magnitude of the group size effect on vigilance? Behav Ecol 19:1361-1368

Blair RB (2001) Birds and butterflies along urban gradients in two ecoregions of the US. In: Lockwood JL, McKinney ML (eds) Biotic Homogenization. Kluwer Academic Publishers, New York, pp 33-56

Blumstein DT (2003) Flight-initiation distance in birds is dependent on intruder starting distance. J Wildl Manage 67:852-857

Blumstein DT (2006) Developing an evolutionary ecology of fear: how life history and natural history traits affect disturbance tolerance in birds. Anim Behav 71:389-399

Breiman L (2001) Random forests. JMLR 45:5-32

Creswell W (1995) Selection of avian prey by wintering sparrowhawks Accipiter nisus in Southern Scotland. Ardea 83:381-389

DeStefano S, Degraaf RM (2008) Exploring the ecology of suburban wildlife. Front Ecol Env 1:95-101

Dunn RR, Gavin MC, Sanchez MC, Solomon JN (2006) The pigeon paradox: dependence of global conservation on urban nature. Cons Biol 20:1814-1816

Fernández-Juricic E (2012) Sensory basis of vigilance behaviour in birds: synthesis and future prospects. Behav Proc 89:143-152

Fernández-Juricic E, Gall MD, Dolan T, Tisdale V, Martin GR (2008) The visual fields of two ground-foraging birds, House Finches and House Sparrows, allow for simultaneous foraging and anti-predator vigilance. Ibis 150:779-787

Fernández-Juricic E, Schroeder N (2003) Do variations in scanning behavior affect tolerance to human disturbance? App Anim Beh Sci 84:219-234

Ford HA, Bell H, Nias R, Noske R (1988) The relationship between ecology and the incidence of cooperative breeding in Australian birds. Behav Ecol Sociobiol 22:239-249

Frid A, Dill LM (2002) Human-caused disturbance stimuli as a form of predation risk. Cons Ecol 6 (11) [http://www.consecol.org/vol6/iss1/art11]

Frith HJ, Brown BK, Barker RD (1974) Food of the crested and common bronzewing Pigeons of inland New South Wales. Aust Wildl Res 1:129-144

Frith HJ, McKean JL, Braithwaite LW (1976) Sexual cycles and food of the doves Streptopelia chinensis and S. senegalensis in Australia. Emu 76:15-24

Guay P-J, Weston MA, Symonds MRE, Glover HK (2013) Brains and bravery: little evidence of a relationship between brain size and flightiness in shorebirds. Aust Ecol 38(5):516-522

Higgins PJ, Davies PJJF (1996) Handbook of Australian, Antarctic and New Zealand Birds. Vol 3 Snipe to Pigeons. Oxford University Press, Melbourne

Lazarus J, Symonds M (1992) Contrasting effects of protective and obstructive cover on avian vigilance. Anim Behav 43:519-521, ance

Liaw A, Wiener M (2002) Classification and regression by random forest. R News 2(3):18-22

Lima SL, Dill LM (1990) Behavioral decisions made under the risk of predation: a review and prospectus. Can J Zool 68:619-640

Lima SL, Bednekoff PA (1999) Temporal variation in danger drives antipredator behaviour: the predation risk allocation hypothesis. Am Nat 153:649-659

Long JL (1981) Introduced Birds of the World. Reed

Magrath R, Lill A (1983) The use of time and energy by the crimson rosella in a temperate wet forest in winter. Aust J Zool 31:903-912

Malakov AA, Immler S, Gonzalez-Voyer A, Ronn J, Kolm N (2011) Brains and the city: big-brained passerine birds succeed in urban environments. Biol Lett 7(5):730-732
Martin P, Bateson P (2007) Measuring Behaviour: An Introductory Guide. Cambridge University Press

McGiffin A, Lill A, Beckman J, Johnstone CP (2013) Tolerance of human approaches by common Mynas along an urban-rural gradient. Emu 113:154-160

Møller AP (2008) Flight distance of urban birds, predation, and selection for urban life. Behav Ecol Sociobiol 63:63-75

Mulhall S, Lill A (2011) What facilitates urban colonisation by Crested Pigeons Ochyphaps lophotes? Corella 35:73-81

Møller AP, Samia DSM, Weston MA, Guay P-J, Blumstein DT (2014) American Exceptionalism: population trends and flight initiation distances in birds from three continents. PLoS One 9(9):e107883, doi:10.1371/journal.pone.0107883

Price M (2008) The impact of human disturbance on birds: a selective review. In: Lunney D, Munn A, Meikle W (eds) Too Close for Comfort: Contentious Issues in Human-Wildlife Encounters. Royal Zoological Society of New South Wales., pp 810-821

Robbins CS (1995) Non-native birds. In: LaRoe ET, Farris GS, Puckett CE, Doran PD, Mac MJ (eds) Our Living Resources: A Report to the Nation on the Distribution, Abundance, and Health of U.S. Plants, Animals and Ecosystems. Department of the Interior, National Biological Service, U.S, pp 437-440

Vines A, Lill A (2015) Boldness and urban dwelling in little ravens. Wildl Res http://dx.doi.org/10.1071/WR14104

Weston MA, McCleod EM, Blumstein DT, Guay P-J (2012) A review of flight initiation distances and their application to managing disturbance to Australian birds. Emu 112:269-286

Zuur AF, leno EN, Smith GM (2007) Analysing ecological data. Springer, Verlag

\section{Submit your next manuscript to BioMed Central and take full advantage of:}

- Convenient online submission

- Thorough peer review

- No space constraints or color figure charges

- Immediate publication on acceptance

- Inclusion in PubMed, CAS, Scopus and Google Scholar

- Research which is freely available for redistribution 